\title{
XVII. Observations on the constituent parts of atmospheric air
}

\section{Count de Morozzo}

To cite this article: Count de Morozzo (1798) XVII. Observations on the constituent parts of atmospheric air, Philosophical Magazine Series 1, 1:4, 417-420, DOI:

10.1080/14786447808676864

To link to this article: http://dx.doi.org/10.1080/14786447808676864

册 Published online: 25 Jan 2010.

Submit your article to this journal $\lceil\pi$

Џ Article views: 2

Q View related articles $\square$ 
The author defcribes, alfo, two forts of crania found in the moffes in the department of $\mathrm{La}$ Somme, and which have a great refemblance to thofe of the urus, which are nearly one fourth larger.

Cit. Cuvier concludes his refearches as follows : I. It is not agreeable to truth to affert that the animals of the fouth have formerly exifted in the north, their fpecies not being perfectly identic. 2. That there have exifted in all countries animals which do not exift at prefent, and that are no where to be found in any known part of the globe. He therefore leaves it to geologifts to make fuch changes or additions, in regard to their fyftems, as they may think neceffary to explain the facts which he has thus eftablifhed.

XVII. Obfervations on the Conftituent Parts of Atmo/pberic Air. By Count de Morozzo. Witb tbe Remarks of F. Van Humboit. From the Journal de Phyfique, Fructidor, 6th Year.

$\mathbf{I}_{\mathrm{N}}$

the memoir which I publifhed in 1784 , on animal refpiration in dephlogifticated or oxygen gas, I offered fone reflections refpecting the conftituent parts of atmofpheric air, founded on experiments I had made. Lavoifier, in his Elementary Treatife of Chemiftry, does not agree with my experiments. That author fays, that the component parts of atmofpheric air are 73 parts of mephitic or azotic gas, and 27 of oxygen gas, eminently refpirable. It will then be feen, adds he, that when animal fubitances are diffolved in the nitric acid, there is difengaged a great quantity of gas, which extinguithes a lighted candle, injures animals, and which has a perfect refemblance to that part of atmofpheric air which is unfit for refpiration. If to 73 parts of this fluid we add 27 of oxygen gas, obtained from mercury reduced to the ftate of an oxyde by calcination, there is formed a Vor. I. É fluid 
flid perfeetly fimilar to that of the atmofphere, and which has all its properties.

The following, on the other hand, are the corollaries which I have deduced from a great number of experiments made to afcertain the duration of animal life in noxious aeriform fluids, mixed in different proportions with oxygen gas, tending to illuftrate the real compoftion of atmofpheric air.

r. The examination by means of burning tapers is not accurate for afcertaining the falubrity of the air. I thall quote only two examples. A fifth part of oxygen gas mixed with air contaminated by the vapour of fulphur; fuffered a candle to burn, while an animal thut up in it died in a few feconds. A feventh part of the fame gas mixed with air vitiated by the vapour of charcoal, fupported flame, while an animal died in it almoft infantaneoufy.

2. That pure and falutary part faid to be conțained in atmorpheric air, which forns a third of it according to Scheele, and a fourth according to Lavoifer, is not a real dephlogifticated oxygen gas; fince this gas united with znephitie airs, in a much lefs proportion than a third or fourth, lupports the flame of a candle after an animal dies in it, which is not the cafe with atmofpheric air.

3. The real component parts of atmofpheric air are ftill unknown; fince, with a mixture of different gafes, nothing has been obtained but compound gafes, which have indeed fome properties of air, but never thofe of atmofpheric air.

The author, to illuftrate the queftion, relates eight characterizing marks of atmofpheric air, acknowledged by phiJofophers; and adds, that though he tried, by a multitude of experiments, to compofe atmofpheric air, by mixing dephlogifticated gas with different mephitic gafes, the gafes fo obtained always contained fomething not to be found in atmofpheric air. 
He repeated the experiments of Lavoifier, by mixing 73 parts of fixed air (carbonic acid gas), obtained from lime, with 27 of gas obtained from the red precipitate. This mixture, indeed, exbibited to him all the characters and properties of atmofpheric air, but it differed confidetably from it in its effential property.

A candle is fuddenly extinguifhed in atmofpheric air in which an animal has died; another animal conld not live in it an inftant. On the othet band, in this artificial mixture; a flame burnt with vivacity; and a fecond animal, a fpar. row, lived 25 minutes, a third 14 or 15 : a light, introduced after the death of the third fparrow, burnt fill with a biright flame. "This mixture then does not form an elaftic, fluid perfectly fimilar to that of atmopperic air, and baviagg all its properties." He tried to add to this mixture phlogifticated gas, inflammable air, and that in which an animal had died. A fecond and third animal lived in them fome time, and a candle was not extinguifhed.

\section{Remarks on the above Obfervations, by F. Von Humbolt.}

The memoir of Count Morozzo treats of a vety important fubject with which I have been engaged for fome months. The Italian philofopher has obferved the difference between natural atmofpheric air and an artificial compound of azot and oxygen; but, in my opinion, he goes too far, in afferting that atmofpheric oxygen is not vital gas ; though I agree with him that we are not able to form an aeriform fluid, fuch as the illuftrious Lavoifier annouinces in his Elements of Chemiftry, perfectly fimilar to that of the atmofphere. I however find that this difficulty confifts neither in our ignorance of the quantity, nor of the quality of the two gafeous bafes. The difference foind between the effect of niatural and artificial atmofpheric air, is to be afcribed to the ftate of the combination in which the oxygen is joined to the azot. The atmofphere is not a mixture: its conftituent parts ought to be confidered as in a fate of chenisal conbi- 


\section{0}

\section{On the Conftituent Parts, 80 :}

nation. It is for this reafon that the two bafes of a pecific gravity fo different, that of azot and that of oxygen, do not entirely feparate from each other, though the high regions are moft charged with azot. Hence azot retains fo ftrongly the laft portion of the oxygen, which phofphorus, the ful. phure of pot-anh, and other acidifiable bafes ought to take from it; and I have for this reafon feen that the nitrous gas acts in proportions very different in decompofing the natural atmofpheric air, or a crmpound of 27 of oxygen and 73 of azot. But how could Morozzo think to imitate the atmofphere by mixing the carbonic acid and oxygen? He has confounded azot with the carbonic acid gas. But he affures us that his atmofpheric air with a carbonic acid bafe, gave the fame fpecific weight as atmofpheric air. Here is a very ftriking experiment: one cubic inch of azot weighing 0,46624 grains, while the fame cubic inch of carbonic acid weighed 0,67500 grains! Morozzo tells us that a eandle burnt in his artificial mixture with a very brilliant Hame (con fiamma lucidiffma). By combining 0,25 of the carbonic acid with 0,75 of oxygen, I have feen a wax taper extinguifhed. The fame thing took place when, in company with Tafleart in Vauquelin's laboratory, I mixed two parts of the carbonic acid gas with ten parts of atmolpheric air. There is then formed a new chemical combination: the carbonic acid lays hold fo ftrongly of the oxygen of the atmofphere, that the affinity prefented by the lighted wax taper is not powerful enough to take it away. In my work on the analyfis of the mephitic vapour of mines, which is about to be tranflated into French, it will be feen that there exifts airs not unfit for refpiration, which are compofed of 0,27 of oxygen, 0,70 of azot, and 0,03 of carbonic acid gas. It is the ftate of the combination, and not always the quantity of oxygen, which renders air more or lefs capable to deftroy animal life, or to extinguifh flame. 